\title{
IDH1 NP_005887.2:p.R119Q
}

National Cancer Institute

\section{Source}

National Cancer Institute. IDH1 NP 005887.2:p.R119Q. NCI Thesaurus. Code C131103.

A change in the amino acid residue at position 119 in the isocitrate dehydrogenase

[NADP] cytoplasmic protein where arginine has been replaced by glutamine. 